\title{
Activating ERBB2 Mutation
}

National Cancer Institute

\section{Source}

National Cancer Institute. Activating ERBB2 Mutation. NCI Thesaurus. Code C129700.

A change in the nucleotide sequence of the ERBB2 gene that that results in constitutive receptor tyrosine-protein kinase erbB-2-dependent signal transduction and activation of downstream signaling pathways. 